J. Lake Sci. (湖泊科学) , 2018, 30(3): 741-752

DOI 10. 18307/2018. 0316

(c) 2018 by Journal of Lake Sciences

\title{
城市河流细菌群落特征及影响因素——鄱阳湖流域赣江南昌段 为例
}

刘君政 ${ }^{1,2}$, 王 鹏 ${ }^{1,2 * *}$, 肖汉玉 ${ }^{1,2}$, 陈 波 ${ }^{1,2}$

( 1 : 江西师范大学鄱阳湖湿地与流域研究教育部重点实验室,南昌 330022)

$(2:$ 江西师范大学地理与环境学院,南昌 330022)

摘 要: 为了了解赣江细菌群落特征, 探讨环境因子对城市河流细菌群落结构组成的影响, 本文基于高通量测序分析鄱 阳湖流域赣江南昌段 2015 年 4 月至 2016 年 3 月 5 个采样点 (G1 G5) 的细菌群落特征. 采用 R 语言“Vegan”程序包中的 “Bioenv”程序、午余分析方法分析环境因子对河水细菌群落的影响, 基于 Bayesian 统计方法的 SourceTracker 模型估算南 昌城区对赣江细菌群落的改变比例. 结果表明. 赣江南昌段的优势菌门为放线菌门 (Actinobacteria, 34.05\%) 和变形菌门 (Proteobacteria, 31.59\%) , 其次为厚壁菌门 (Firmicutes, 15.49\%) 和拟杆菌门 (Bacteroidetes, 9.12\%); 气温和流量是河流细 菌群落主要影响因子, 其中气温是影响 OTU 丰度的最佳单参数, 影响门丰度的最佳单参数是流量; 水文气象条件 (气温和 流量) 对河流细菌群落的影响大于水化学指标, 包括营养盐 (溶解有机碳、总磷和铵态氮) 、水化学离子 $\left(\mathrm{HCO}_{3}^{-} 、 \mathrm{Cl}^{-} 、 \mathrm{NO}_{3}^{-}\right.$、 $\mathrm{SO}_{4}^{2-} 、 \mathrm{Na}^{+} 、 \mathrm{~K}^{+}$和 $\left.\mathrm{Mg}^{2+}\right)$ 和重金属元素 $(\mathrm{Mn} 、 \mathrm{Cd} 、 \mathrm{Cr} 、 \mathrm{~Pb} 、 \mathrm{Cu} 、 \mathrm{As} 、 \mathrm{Ba}$ 和 $\mathrm{Fe})$. 除 Proteobacteria 外, 其余门的细菌相对丰度在 5 个采样点之间不存在显著差异; SourceTracker 模型结果表明南昌城区对赣江细菌群落结构组成的影响为 $6.33 \%$ $34.67 \%$, 对赣江南支细菌群落的影响显著高于其他河段; 南昌城区对细菌群落的影响较小, 主要的影响门类为 Proteobacteria.

关键词: 细菌群落结构;高通量测序;水文气象;水化学;南昌城区; 赣江; 鄱阳湖流域

Characteristics of aquatic bacterial community and the influencing factors in an urban river-A case study of Nanchang section of the Ganjiang River, Lake Poyang Basin

\author{
LIU Junzheng ${ }^{1,2}$, WANG Peng ${ }^{1,2 * *}$, XIAO Hanyu ${ }^{1,2} \&$ CHEN Bo ${ }^{1,2}$ \\ (1: Key Laboratory of Lake Poyang Wetland and Watershed Research, Ministry of Education, Jiangxi Normal University, Nan- \\ chang 330022, P.R.China) \\ (2: School of Geography and Environment, Jiangxi Normal University, Nanchang 330022, P.R.China)
}

\begin{abstract}
In this study, we analyzed the characteristics of the bacterial community in Nanchang section of the Ganjiang River, Lake Poyang Basin, based on monthly sampling on five sites (G1-G5) from April 2015 to March 2016. G1 lays on the Ganjiang River before entering the urban region, G2 in the center of the city, and G3-G5 in the three branches leaving the urban region, respectively. The hydrometeorological factors ( air temperature and flow rate) were recorded; the hydrochemical factors of sampling water, including nutrients (dissolved organic carbon, total phosphorus and ammonium nitrogen), ions $\left(\mathrm{HCO}_{3}^{-}, \mathrm{Cl}^{-}, \mathrm{NO}_{3}^{-}\right.$, $\mathrm{SO}_{4}^{2-}, \mathrm{Na}^{+}, \mathrm{K}^{+}$and $\mathrm{Mg}^{2+}$ ), and heavy metals $(\mathrm{Mn}, \mathrm{Cd}, \mathrm{Cr}, \mathrm{Pb}, \mathrm{Cu}, \mathrm{As}, \mathrm{Ba}$ and $\mathrm{Fe}$ ) were measured. The bacterial community was characterized using Illumina high-throughput sequencing. Nonmetric Multidimensional Scaling ( NMDS) was carried out on OTUs data using Bray-Curtis distance matrices to examine the difference in bacterial community between water samples. The 'Bioenv' in the R package 'Vegan' and redundancy analysis was used to explore the influence of environmental factors on the bacterial community in the river. The SourceTracker Model, which was based on Bayesian Statistical Method, was used to estimate the change of bacterial community in Nanchang section of the Ganjiang River. Results showed that: The dominant phyla were Acti-
\end{abstract}

* 国家自然科学基金项目 (41661017) 和江西省自然科学基金项目 (20151BAB213035) 联合资助. 2017-06-24 收稿; 2017-08-27 收修改稿. 刘君政(1991 ),女,硕士研究生;E-mail : liujunzheng@126.com.

** 通信作者;E-mail: wangpengjlu@ jxnu.edu.cn. 
nobacteria (34.05\%) and Proteobacteria (31.59\%), followed by Firmicutes (15.49\%) and Bacteroidetes (9.12\%). Air temperature and flow rate were the main environmental factors influencing bacterial communities in the river. The optimal single-parameter for explaining the variance of OTU abundance was air temperature, and the optimal single-parameter for explaining the variance of phylum abundance was flow rate. The influence of hydrometeorological factors ( air temperature and flow rate) on bacterial communities was higher than that of the water chemistry. Except for Proteobacteria, there was no significant difference of the bacterial community between the five sampling sites. The results of SourceTracker Model showed that the influence of Nanchang city on the bacterial community in the Ganjiang River ranged from $6.33 \%$ to $34.67 \%$, and the influence on bacterial community in the south branch of the Ganjiang River was significantly higher than that in other river sections. The influence of Nanchang city on bacterial community was small, and the main influenced phylum was Proteobacteria.

Keywords: Bacterial community; the high throughput sequencing; hydrometeorological; water chemistry; Nanchang City; Ganjiang River; Lake Poyang Basin

细菌是生态系统的重要组成部分, 是能量流动和营养物质交换的重要环节. 河流水体细菌多样性是水 质评价的重要指标, 能够体现水体受污染程度和污染物在河水中的迁移转化规律 ${ }^{[1]}$. 高通量测序技术能够 同时对稀有、优势物种进行深度测序,已成为检测细菌群落的常用工具 ${ }^{[2-3]}$.

河流细菌群落结构组成受多种因素的影响. 水体滞留时间 ${ }^{[4]}$ 、营养盐浓度 ${ }^{[5-8]}$ 、溶解有机碳 $(\text { DOC })^{[9-11]}$ 和河流的补给来源 ${ }^{[12]}$ 等都会影响细菌群落结构组成,但不同研究得到的结论有较大差异: 多次采样研究中 得到的细菌群落结构组成主要影响因素往往是水文气象因素 ${ }^{[13-15]}$; 单次采样中得到影响细菌群落结构组成 的主要因素往往是水化学指标 ${ }^{[5-8,16]}$. 这主要是由于单次采样难以分析气温、流量等水文气象因素的变化. 城市废水的排放会导致污水细菌直接进人河流, 这些污染菌株类型主要为 Proteobacteria、Actinobacteria、Firmicutes 和 Bacteroidtes ${ }^{[17-19]}$, 此外废水排放也可能通过改变河水物理化学参数影响细菌群落 ${ }^{[20]}$.

赣江是江西省最大的河流, 也是长江的第二大支流. 随着流域内人口增加和社会经济发展, 赣江水环境 存在恶化的趋势 ${ }^{[21-22]}$. 目前赣江流域水环境研究主要集中于氮磷时空分布 ${ }^{[23]}$ 、非点源污染负荷 ${ }^{[24]}$ 、土地利 用方式对水质的影响 ${ }^{[25]}$ 和重金属分布 ${ }^{[26]}$ 等方面. 赣江水体细菌群落的研究较少, 细菌群落结构组成特征及 其影响因素尚不清楚. 赣江经南昌后分成 3 支注人鄱阳湖, 是鄱阳湖水体的主要补给源, 阐明赣江南昌段的 细菌群落特征和影响因素对南昌市饮用水安全及鄱阳湖水环境保护具有重要意义. 本次研究基于每月采样 ( 2015 年 4 月- 2016 年 3 月), 分析赣江南昌段细菌群落结构组成特征及影响因素. 主要研究目的为: (1) 赣 江南昌段水体细菌群落结构组成特征; (2) 确定河水中影响细菌群落结构组成主要环境变量, 比较水文气象 因素 (气温和流量) 与水化学指标 (营养盐、水化学离子和重金属元素) 对细菌群落结构组成的影响差异; (3) 量化南昌城区对河流细菌群落结构组成的影响.

\section{1 材料与方法}

\section{1 样品收集和水化学分析}

赣江流域面积占鄱阳湖流域面积的 $50.60 \%$. 流域内平均气温为 $17.60^{\circ} \mathrm{C}$, 年平均降水量为 $1524.60 \mathrm{~mm}$. 降水丰沛但不均, $4-6$ 月份多年平均降水量占全年降水的 $41 \% \sim 51 \%$. 赣江进人南昌城区后分为南支、中 支、北支 3 条支流注人鄱阳湖 (图 1). 南支环绕老城区和高新技术开发区, 中支主要流经郊区农田, 北支流 经新城区和城郊农业.

本次采样点 $(G 1 \sim G 5)$ 设置为: $G 1$ 位于赣江进人城区前, G2 位于城区中心, $G 3 \sim G 5$ 分别位于城区下游 的赣江南支、中支和北支. 在 2015 年 4 月- 2016 年 3 月, 每月中旬在河道中心约 $50 \mathrm{~cm}$ 深度采集水样, 共计 60 个. 使用便携式电导率仪 (哈纳, HI98360) 现场测定电导率 (EC) ; 使用全自动间断分析仪 (Smartchem 200 Brookfield, 美国) 测定铵态氮 ( $\mathrm{NH}_{4}^{+}-\mathrm{N}$ ) 和总磷 (TP) 浓度; 使用 TOC 分析仪 (Shimadzu TOC-L CPH, 日本) 测定 DOC 浓度; 使用等离子体发射仪 (Optima 800PerkinElmer, 美国) 测定 $\mathrm{K}^{+} 、 \mathrm{Na}^{+} 、 \mathrm{Mg}^{2+}$ 浓度; 采用 ICS-2100 离子 色谱系统测定 $\mathrm{Cl}^{-} 、 \mathrm{NO}_{3}^{-} 、 \mathrm{SO}_{4}^{2-}$ 浓度; 采用酸碱指示剂滴定法测定 $\mathrm{HCO}_{3}^{-}$浓度; 采用电感耦合等离子体制谱 $(\mathrm{X}$ series II , Thermo, 美国) 测定重金属 $\mathrm{Mn} 、 \mathrm{Cd} 、 \mathrm{Cr} 、 \mathrm{~Pb} 、 \mathrm{Cu} 、 \mathrm{As} 、 \mathrm{Ba} 、 \mathrm{Fe}$ 浓度. 用于测定 $\mathrm{NH}_{4}^{+}-\mathrm{N}$ 和 DOC 浓度的水 样通过 $0.45 \mu \mathrm{m}$ 滤膜过滤 (新亚, 中国). 用于细菌高通量测序的水样 $(3 \mathrm{~L}$ ) 先通过 $5 \mu \mathrm{m}$ 滤膜过滤悬浮杂质, 
然后再通过 $0.22 \mu \mathrm{m}$ 滤膜过滤, 将滤膜于 $-80^{\circ} \mathrm{C}$ 下保 存待用.

以外洲站(图 1) 早 8:00 时的流量 (南昌信息水 文网 http: // www. jxncsw. com/list. jsp? classid = 19) 作为采样日赣江流量, 同时记录采样日的气温. 2015－2016 年是超强“厄尔尼诺”年,降水异常 ${ }^{[27]}$, $11 、 12$ 和 1 月采样前出现连续性降水, 导致流量较 往年偏高; 相比于研究区正常年份下雨热同期的季 风气候, 本次研究中较低气温月份异常及较大流量 月份异常的出现有利于区分气温与流量对细菌群落 的影响.

\subsection{DNA 的提取和测序}

利用 E.Z.N.A. ${ }^{\circledR}$ Soil DNA Kit (Omega Bio-tek, Norcross, GA, U.S.) 提取基因组 DNA, 利用 1\% 琼脂 糖凝胶电泳检测抽提 DNA. 利用引物扩增 $16 \mathrm{~S}$ rRNA 基因的 V3 $\sim \mathrm{V} 4$ 高变区, 引物序列为 $338 \mathrm{~F}$ ( $5^{\prime}$ ACTCCTACGGGAGGCAGCA- $3^{\prime}$ ) 和 806R ( $5^{\prime}$-GGACTACHVGGGTWTCTAAT-3'). PCR 扩增条件为: $95^{\circ} \mathrm{C}, 2 \mathrm{~min} ;\left(95^{\circ} \mathrm{C}, 30 \mathrm{~s} ; 55^{\circ} \mathrm{C}, 30 \mathrm{~s} ; 72^{\circ} \mathrm{C}, 30 \mathrm{~s}\right), 60$ 个循环; $72^{\circ} \mathrm{C}, 5 \mathrm{~min}$. 获得扩增产物后, 使用 AxyPrepDNA 凝胶回收试剂盒( Axygen 公司) 切胶纯 化, 混合后用 TrisHCl 洗脱. 进一步通过 $2 \%$ 琼脂糖 电泳检测 PCR 产物纯化效果, 测定纯化后 PCR 产 物的浓度. 参照电泳初步定量结果, 将 PCR 产物用

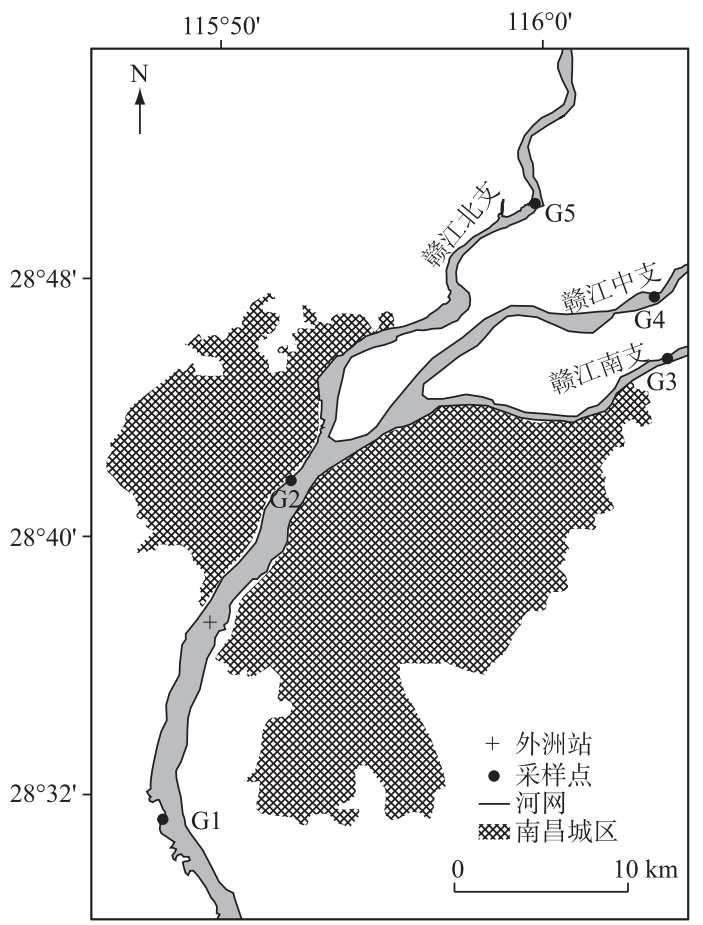

图 1 赣江南昌段采样点位置

Fig. 1 Location of sampling sites in the Nanchang section of the Ganjiang River QuantiFluorTM-ST 蓝色苂光定量系统 (Promega 公司) 进行检测定量, 按照每个样本的测序量要求, 进行相应 比例的混合. 在上海美吉生物医药科技有限公司 Illumina MiseqPE300 平台进行测序. 原始序列数据提交至 NCBI SRA 数据库( 登陆号:SRP074362 和 SRP113212).

\section{3 统计分析}

本文利用 FLASH 和 Trimmomatic 软件对原始 DNA 序列进行过滤处理, 去除嵌合体, 得到优化序列. 利 用 UPARSE 软件按照 $97 \%$ 相似性将优化序列划分可操作分类单元 (OTU, Operational Taxonomic Units). 采 用 RDP classifier 贝叶斯算法对照 Silva 数据库以 70\% 置信度对 OTU 代表序列进行物种分类. 为避免各样品 微生物量的差异,按最小样本序列数进行样本序列抽平处理,得到标准化数据进行后续统计分析.

通过 Chaol 丰度指数和 Shannon 多样性指数分析 $\alpha$ 多样性. 通过 OTUs 表生成的 Bray-Curtis ${ }^{[28]}$ 距离矩 阵分析 $\beta$ 多样性. 采用单因素方差分析判断不同月份、不同采样点多样性指数和门、属水平分类细菌丰度的 差异. 使用 Bray-Curtis 距离矩阵对 OTUs 数据进行非度量多维尺度 (NMDS, Nonmetric Multidimensional Scaling) 分析,分析不同条件下细菌群落结构组成的差异性.

使用 R 语言“Vegan” ${ }^{[29]}$ 包中的“Bioenv” ${ }^{[30]}$ 程序确定不同环境因子(包括水文气象指标:气温和流量; 水化学指标:营养盐、水化学离子和重金属元素)对细菌群落的影响. 使用攵余分析 (RDA, Redundancy analysis) 探讨门分类细菌与环境因子之间的关系. 使用 SourceTracker ${ }^{[31]}$ 模型估测南昌城区对细菌群落的影响, SourceTracker 模型是基于 Bayesian 统计方法定量计算微生物群落来源混合比例的模型, 已成功应用于估算 水体微生物中粪便来源比例 ${ }^{[32-33]}$ 和不同来源对水体细菌群落动态扩散的影响差异 ${ }^{[34]}$. 本次研究中将 $\mathrm{G} 1$ (人城前) 水体细菌视为 G2 G5 处水体细菌的来源, 利用 SourceTracker 模型计算 G2 G5 处水体细菌群落相 对于 G1 的改变,将这种改变视为南昌城区对赣江细菌群落的影响.

Newton 等 ${ }^{[33]}$ 研究发现 Acinetobacter、Arcobacter 和 Trichococcus 是城市污水的指示细菌, $\mathrm{Ye}$ 等 ${ }^{[17]}$ 发现 $M y$ - 
cobacterium 和 Vibrio 在城市污水中广泛存在; 以上 5 种细菌在本次研究中检测出 Acinetobacter (Proteobacteria)、Arcobacter (Proteobacteria) 和 Mycobacterium (Actinobacteria), 选择以上 3 种细菌作为本次研 究的污水指示细菌; 污水指示细菌的丰度可以体现城区对细菌群落的影响, 通过不同采样点污水指示菌的 变化验证 SourceTracker 模型的计算结果.

\section{2 结果与分析}

\section{1 水化学特征与水文特征}

不同月份采样日赣江流量差异很大, 从 4 月的 $1060 \mathrm{~m}^{3} / \mathrm{s}$ 到 5 月的 $8260 \mathrm{~m}^{3} / \mathrm{s}$. 在 5 月份采样日之前, 整

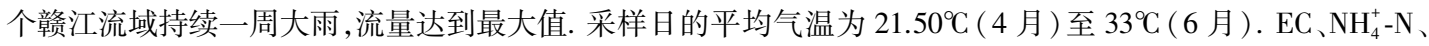
$\mathrm{HCO}_{3}^{-} 、 \mathrm{NO}_{3}^{-} 、 \mathrm{SO}_{4}^{2-} 、 \mathrm{Na}^{+} 、 \mathrm{~K}^{+} 、 \mathrm{Mg}^{2+}$ 等指标在 4 月的 $\mathrm{G} 3$ 采样点出现最大值. $\mathrm{K}^{+} 、 \mathrm{EC} 、 \mathrm{SO}_{4}^{2-} 、 \mathrm{NH}_{4}^{+}-\mathrm{N} 、 \mathrm{Ba}$ 和 $\mathrm{Fe}$ 等指 标在 $\mathrm{G} 1$ 采样点出现最小值. $\mathrm{DOC} 、 \mathrm{Cl}^{-} 、 \mathrm{~K}^{+} 、 \mathrm{Cr} 、 \mathrm{As} 、 \mathrm{Ba}$ 和 $\mathrm{Fe}$ 等指标在不同采样点间没有显著差异. TP、 $\mathrm{NH}_{4}^{+}-\mathrm{N} 、 \mathrm{SO}_{4}^{2-} 、 \mathrm{~Pb} 、 \mathrm{EC}$ 等指标在 $\mathrm{G} 3$ 采样点显著高于其他采样点. $\mathrm{G} 3$ 采样点的 $\mathrm{HCO}_{3}^{-} 、 \mathrm{NO}_{3}^{-} 、 \mathrm{Na}^{+} 、 \mathrm{Mg}^{2+}$ 和 $\mathrm{Cu}$ 浓 度显著高于 G4 采样点. G1 采样点的 Cd 浓度显著高于 G4 和 G3 采样点. G5 采样点的 Mn 浓度显著高于 G3、G1、G4 和 G2 采样点 (表 1).

\section{表 1 赣江水体水化学指标 *}

Tab.1 Water chemistry index in the Ganjiang River

\begin{tabular}{|c|c|c|c|c|c|c|}
\hline \multirow{2}{*}{ 水化学指标 } & & \multicolumn{5}{|c|}{ 采样点 } \\
\hline & & G1 & G2 & G3 & G4 & G5 \\
\hline 电导率/ $(\mu \mathrm{S} / \mathrm{cm})$ & $\mathrm{EC}$ & $59.72 \pm 13.16^{\mathrm{b}}$ & $60.08 \pm 12.75^{b}$ & $76.42 \pm 21.17^{\mathrm{a}}$ & $62.86 \pm 14.33^{\mathrm{b}}$ & $63.38 \pm 13.21^{\mathrm{b}}$ \\
\hline \multirow[t]{3}{*}{ 营养盐/(mg/L) } & DOC & $5.97 \pm 3.07^{\mathrm{a}}$ & $5.69 \pm 2.66^{\mathrm{a}}$ & $5.80 \pm 2.63^{\mathrm{a}}$ & $7.06 \pm 3.01^{\mathrm{a}}$ & $7.09 \pm 4.67^{\mathrm{a}}$ \\
\hline & $\mathrm{TP}$ & $0.06 \pm 0.02^{b}$ & $0.06 \pm 0.03^{b}$ & $0.10 \pm 0.04^{\mathrm{a}}$ & $0.05 \pm 0.03^{b}$ & $0.06 \pm 0.03^{b}$ \\
\hline & $\mathrm{NH}_{4}^{+}-\mathrm{N}$ & $0.33 \pm 0.12^{\mathrm{b}}$ & $0.35 \pm 0.15^{\mathrm{b}}$ & $0.61 \pm 0.29^{\mathrm{a}}$ & $0.31 \pm 0.10^{\mathrm{b}}$ & $0.38 \pm 0.13^{b}$ \\
\hline \multirow[t]{7}{*}{ 水化学离子 $/(\mathrm{mg} / \mathrm{L})$} & $\mathrm{HCO}_{3}^{-}$ & $36.49 \pm 5.09^{\mathrm{ab}}$ & $35.28 \pm 4.99^{\mathrm{b}}$ & $40.16 \pm 7.37^{\mathrm{a}}$ & $35.15 \pm 5.12^{\mathrm{b}}$ & $37.85 \pm 4.71^{\mathrm{ab}}$ \\
\hline & $\mathrm{Cl}^{-}$ & $7.86 \pm 3.09^{\mathrm{a}}$ & $7.57 \pm 2.79^{\mathrm{a}}$ & $8.62 \pm 3.13^{\mathrm{a}}$ & $7.46 \pm 2.54^{\mathrm{a}}$ & $7.35 \pm 2.50^{\mathrm{a}}$ \\
\hline & $\mathrm{NO}_{3}^{-}$ & $4.42 \pm 1.11^{\mathrm{ab}}$ & $4.46 \pm 1.19^{\mathrm{ab}}$ & $5.43 \pm 2.23^{\mathrm{a}}$ & $4.14 \pm 1.11^{\mathrm{b}}$ & $4.34 \pm 1.00^{\mathrm{ab}}$ \\
\hline & $\mathrm{SO}_{4}^{2-}$ & $10.58 \pm 2.03^{\mathrm{b}}$ & $10.55 \pm 1.91^{\mathrm{b}}$ & $14.30 \pm 4.38^{\mathrm{a}}$ & $10.27 \pm 1.70^{\mathrm{b}}$ & $10.63 \pm 1.41^{\mathrm{b}}$ \\
\hline & $\mathrm{Na}^{+}$ & $5.58 \pm 2.02^{\mathrm{ab}}$ & $5.42 \pm 1.76^{\mathrm{ab}}$ & $6.85 \pm 2.75^{\mathrm{a}}$ & $5.14 \pm 1.67^{\mathrm{b}}$ & $5.09 \pm 1.38^{\mathrm{b}}$ \\
\hline & $\mathrm{K}^{+}$ & $2.72 \pm 0.59^{\mathrm{a}}$ & $2.74 \pm 0.47^{\mathrm{a}}$ & $3.09 \pm 0.71^{\mathrm{a}}$ & $2.71 \pm 0.46^{\mathrm{a}}$ & $2.77 \pm 0.41^{\mathrm{a}}$ \\
\hline & $\mathrm{Mg}^{2+}$ & $2.19 \pm 0.34^{\mathrm{b}}$ & $2.22 \pm 0.41^{\mathrm{ab}}$ & $2.65 \pm 0.80^{\mathrm{a}}$ & $2.15 \pm 0.43^{b}$ & $2.26 \pm 0.43^{\mathrm{ab}}$ \\
\hline \multirow[t]{8}{*}{ 重金属元素/ $(\mu \mathrm{g} / \mathrm{L})$} & $\mathrm{Mn}$ & $8.16 \pm 4.04^{\mathrm{b}}$ & $5.70 \pm 3.34^{\mathrm{b}}$ & $14.14 \pm 8.12^{\mathrm{b}}$ & $6.68 \pm 4.36^{\mathrm{b}}$ & $42.56 \pm 71.27^{\mathrm{a}}$ \\
\hline & $\mathrm{Cd}$ & $0.09 \pm 0.05^{\mathrm{a}}$ & $0.08 \pm 0.02^{\mathrm{ab}}$ & $0.05 \pm 0.03^{c}$ & $0.06 \pm 0.02^{\mathrm{be}}$ & $0.07 \pm 0.02^{\mathrm{abc}}$ \\
\hline & $\mathrm{Cr}$ & $2.93 \pm 1.39^{\mathrm{a}}$ & $2.98 \pm 1.49^{\mathrm{a}}$ & $3.04 \pm 1.58^{\mathrm{a}}$ & $2.73 \pm 1.29^{\mathrm{a}}$ & $2.81 \pm 1.29^{\mathrm{a}}$ \\
\hline & $\mathrm{Pb}$ & $0.87 \pm 0.91^{\mathrm{b}}$ & $1.67 \pm 1.55^{\mathrm{b}}$ & $12.14 \pm 24.83^{\mathrm{a}}$ & $1.44 \pm 1.23^{\mathrm{b}}$ & $1.83 \pm 3.20^{\mathrm{b}}$ \\
\hline & $\mathrm{Cu}$ & $3.80 \pm 3.66^{\mathrm{b}}$ & $7.46 \pm 9.43^{b}$ & $109.86 \pm 228.26^{\mathrm{a}}$ & $4.41 \pm 4.05^{\mathrm{b}}$ & $23.60 \pm 63.04^{\mathrm{ab}}$ \\
\hline & As & $1.72 \pm 0.61^{\mathrm{a}}$ & $1.73 \pm 0.62^{\mathrm{a}}$ & $1.64 \pm 0.55^{\mathrm{a}}$ & $1.46 \pm 0.42^{\mathrm{a}}$ & $1.55 \pm 0.42^{\mathrm{a}}$ \\
\hline & $\mathrm{Ba}$ & $173.89 \pm 39.28^{\mathrm{a}}$ & $170.90 \pm 31.81^{\mathrm{a}}$ & $189.52 \pm 36.28^{\mathrm{a}}$ & $183.52 \pm 28.69^{\mathrm{a}}$ & $186.03 \pm 31.93^{\mathrm{a}}$ \\
\hline & $\mathrm{Fe}$ & $111.21 \pm 42.56^{\mathrm{a}}$ & $115.08 \pm 35.49^{\mathrm{a}}$ & $119.63 \pm 49.60^{\mathrm{a}}$ & $114.56 \pm 52.64^{\mathrm{a}}$ & $134.81 \pm 73.78^{\mathrm{a}}$ \\
\hline
\end{tabular}

*表中同一行上标不同字母表示采样点间差异显著 ( LSD 检验, $P<0.05$ ).

\section{2 细菌多样性及群落结构特征}

单个样品序列数范围为 17949 46264( 图 2a), 抽平处理后得到的 OTU 数量范围为 377 784( 图 2b), Chao1 丰度指数范围为 497 1037 (图 2c), Shannon 多样性指数范围为 2.98 4.80( 图 2d). 单因素方差分析 显示 Chao1 丰度指数、Shannon 多样性指数和样品序列数在不同采样点间没有显著差异 $(P=0.790 ; P=$ $0.393 ; P=0.445)$, 但在采样月份之间差异显著 $(P<0.001 ; P=0.031 ; P<0.001)$. 抽平处理后得到的 OTU 数量 在不同采样点间有显著差异 $(P<0.001)$, 但在采样月份之间没有显著差异 $(P=0.187)$. Chao1 丰度指数与 
$\mathrm{Mn} 、 \mathrm{EC} 、 \mathrm{HCO}_{3}^{-} 、 \mathrm{Cl}^{-} 、 \mathrm{NO}_{3}^{-} 、 \mathrm{SO}_{4}^{2-} 、 \mathrm{Na}^{+} 、 \mathrm{~K}^{+} 、 \mathrm{Mg}^{2+}$ 和气温均呈显著负相关; 与 DOC 和流量均呈正相关. Shannon 多 样性指数与 $\mathrm{NO}_{3}^{-} 、 \mathrm{SO}_{4}^{2} 、 \mathrm{NH}_{4}^{+}-\mathrm{N}$ 均呈正相关,与 $\mathrm{TP}$ 和流量均呈负相关.
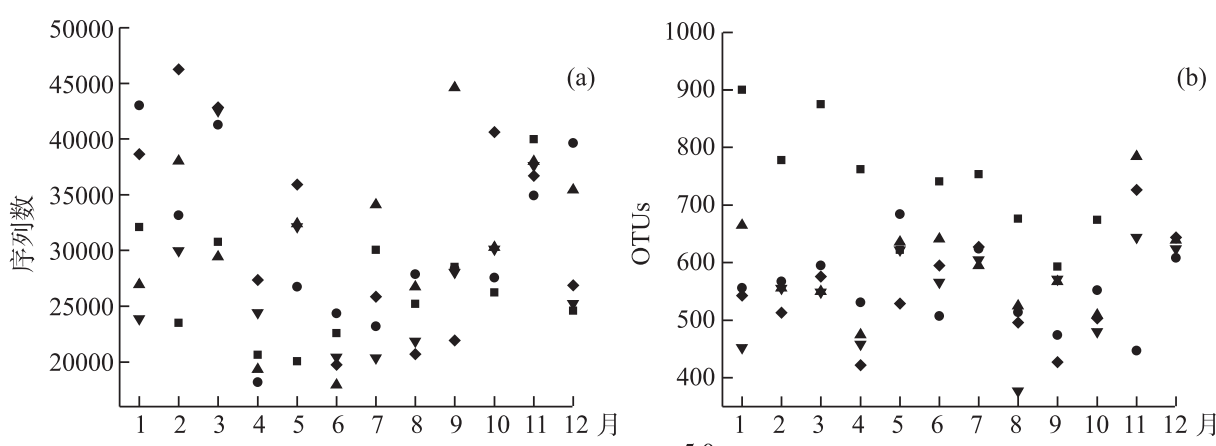

(b)
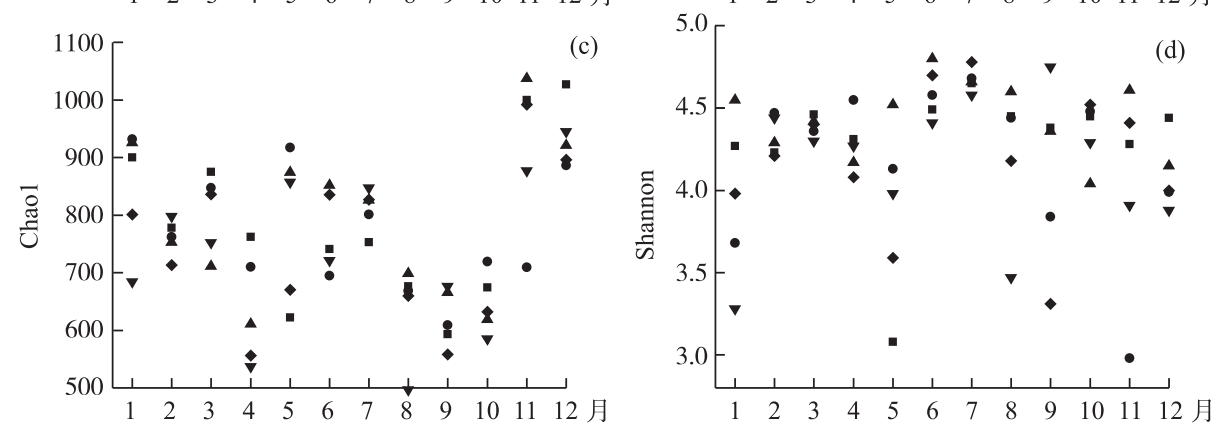

采样点

- G1

- G2

- $\mathrm{G} 3$

- G4

- G5

图 2 样品序列数 ( a ) 、抽平处理后得到的 OTU 数量 (b) 和细菌群落结构组成多样性指数 (Chao1 丰度指数 (c) ; Shannon 多样性指数 (d)) 分布 (1-3 月为 2016 年采样数据; $4-12$ 月为 2015 年采样数据)

Fig.2 The number of sample sequences (a), OTUs (b) and bacterial community abundance and diversity index (Chaol abundance index (c); Shannon diversity index (d))

NMDS 分析 (图 3a、b) 表明, 竷江不同采样点间细菌群落结构组成没有明显差异, 相同月份的采样点具 有类似的细菌群落结构组成. $6 、 7$ 和 10 月细菌群落结构组成较为类似, 2 和 3 月的细菌群落结构组成也具 有相似性, 而 $1 、 4 、 5 、 8 、 9 、 11$ 和 12 月差异较大. 径流量较大时与径流量较小时的细菌群落结构组成有明显差 异 (图 3c) , 气温较低时与气温较高时细菌群落结构组成也有明显差异 (图 3d).

\section{3 门、属水平细菌群落结构组成}

细菌群落的门水平分类中相对丰度最高的是放线菌门 (Actinobacteria, 34.05\%), 第 2 大门是变形菌门 (Proteobacteria, 31.59\%) , 其次是厚壁菌门 (Firmicutes, 15.49\%)、拟杆菌门(Bacteroidetes, 9.12\%) 和蓝细菌 门 (Cyanobacteria, 3.43\% ). Proteobacteria 中 Betaproteobacteria 相对丰度最高, 占细菌总序列数的 $15.24 \%$, 其 次是 Alphaproteobacteria (10.42\%)、Gammaproteobacteria ( 7.30\%)、Deltaproteobacteria (4.31\%) 和 Epsilonproteobacteria $(0.95 \%)$. Firmicutes 的相对丰度在流量较大的 5 月 ( 44.05\%)、11 月 ( 42.34\%)、12 月 ( 36.01\%) 和 1 月 (38.42\%) 很高, 尤其是在流量最大的 5 月份成为水样中相对丰度最高的门(图 4 ). 单因素方差分析表 明,除 $\operatorname{Proteobacteria}(P=0.016)$ 外,其余门的细菌相对丰度在 5 个采样点之间不存在显著差异.

细菌群落的属水平分类中相对丰度最高的是 hgcI_clade(Actinobacteria, 13.29\%), 其次是 Sporichthyaceae _unclassified ( 6.97\% )、CL500-29 _ marine _ group (Actinobacteria, 6.21\% )、Limnohabitans ( Proteobacteria, 6.12\% )、Bacillus (Firmicutes, 5.64\%) 和 Lactococcus (Firmicutes, 5.29\%). Bacillus 丰度只在 $11 、 12$ 和 1 月 ( 5.90\% 34.73\% ) 较高, 其他月份低于 7.87\% ; Lactococcu 丰度只在 5 月 ( $14.54 \% \sim 52.05 \%)$ 较高, 其他月份低 于 10.16\% (图 5). 单因素方差分析表明, 除 Pseudarcicella $(P=0.004)$ 外, 其余属的细菌相对丰度在 5 个采样 点之间不存在显著差异. 

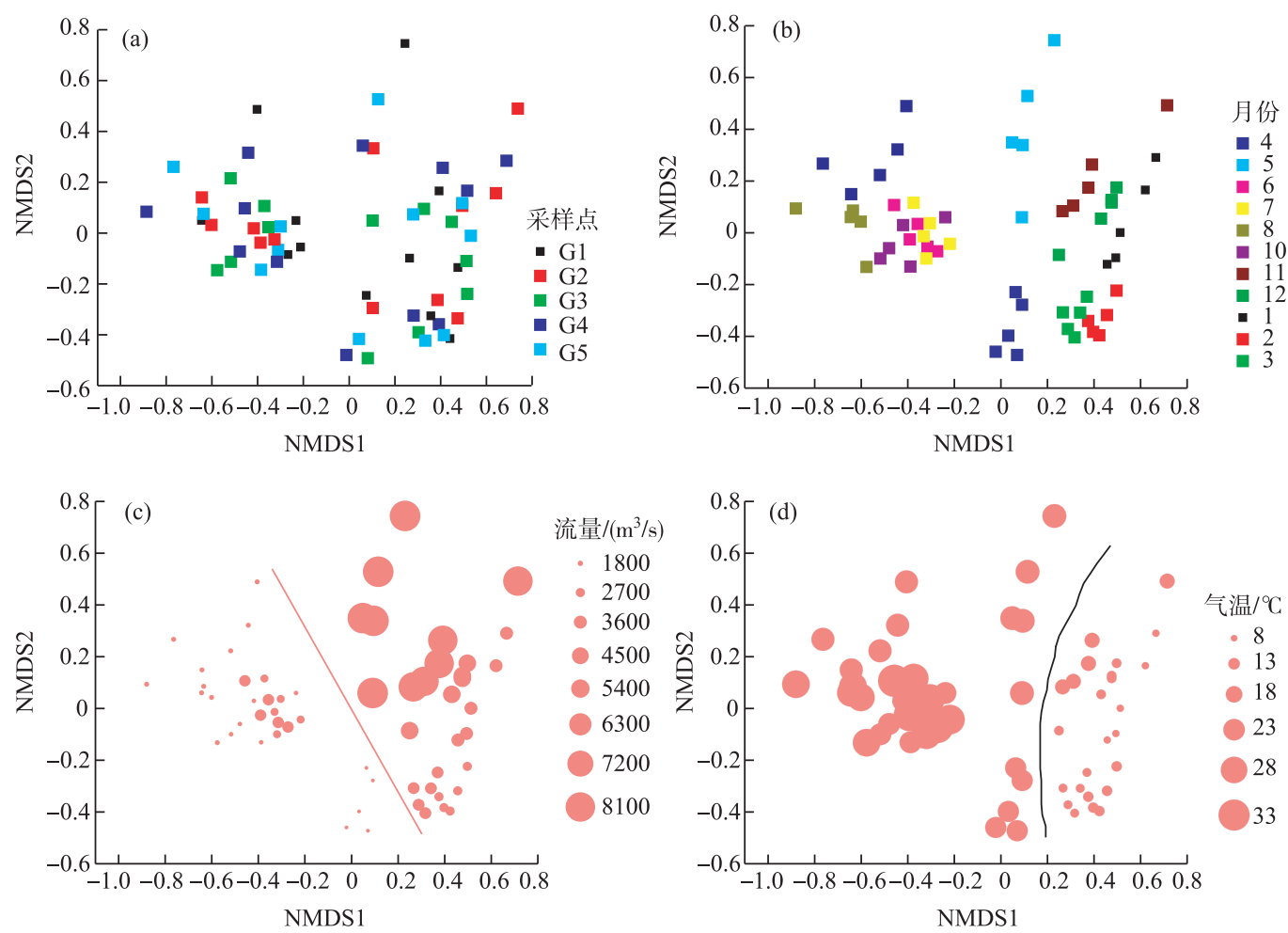

图 3 基于 Bray-Curtis 距离非度量多维尺度 (NMDS) 分析: 细菌群落结构组成在采样点之间的差异性(a)； 细菌群落结构组成在月份之间的差异性 (b) ; 流量对细菌群落结构组成的影响 (c);

气温对细菌群落结构组成的影响 (d)

Fig.3 Nonmetric Multidimensional Scaling ( NMDS) plots derived from Bray-Curtis dissimilarity between water samples : bacterial community between sample ID (a); bacterial community between months (b) ; the influence of flow rate on bacterial community (c); the influence of temperature on bacterial community (d)

\section{4 环境变量对细菌群落的影响}

表 2 为不同环境因子组合对 OTU 分类水平和门分类水平细菌群落结构组成的影响 ( OTU 可视为细菌 群落结构组成的最小分类单元, 门分类为细菌群落结构组成的最大分类单元). 解释 OTU 水平细菌群落结 构组成的最佳单参数是气温 (相关系数 $=0.5738$ ), 而解释门分类水平细菌群落结构组成的最佳单参数是流 量 (相关系数 $=0.5111)$. 气温、流量、EC 和 DOC 是影响 OTU 水平细菌群落结构组成的最佳环境因子组合

表 2 细菌群落与不同环境因子组合的相关关系

Tab.2 Correlations between different combinations of environmental variables and bacterial community

\begin{tabular}{|c|c|c|c|}
\hline \multicolumn{2}{|c|}{ OTU 丰度和环境因子 } & \multicolumn{2}{|c|}{ 门分类细菌与环境因子 } \\
\hline 环境因子组合 & 相关系数 & 环境因子组合 & 相关系数 \\
\hline 气温 & 0.5738 & 流量 & 0.5111 \\
\hline 气温+流量 & 0.6025 & 流量+气温 & 0.5628 \\
\hline 气温+流量 $+\mathrm{Cl}^{-}$ & 0.6245 & 流量+气温+DOC & 0.5932 \\
\hline 气温+流量+EC+DOC & 0.6249 & 流量+气温+DOC+Cl- & 0.5751 \\
\hline 气温+流量+EC+DOC+Cl- & 0.6230 & 流量+气温+DOC+Cl- $+\mathrm{EC}$ & 0.5378 \\
\hline 气温+流量+EC+DOC+Cl- $+\mathrm{NH}_{4}^{+}-\mathrm{N}$ & 0.5979 & 流量+气温 $+\mathrm{DOC}+\mathrm{Cl}^{-}+\mathrm{EC}+\mathrm{NH}_{4}^{+}-\mathrm{N}$ & 0.4735 \\
\hline
\end{tabular}




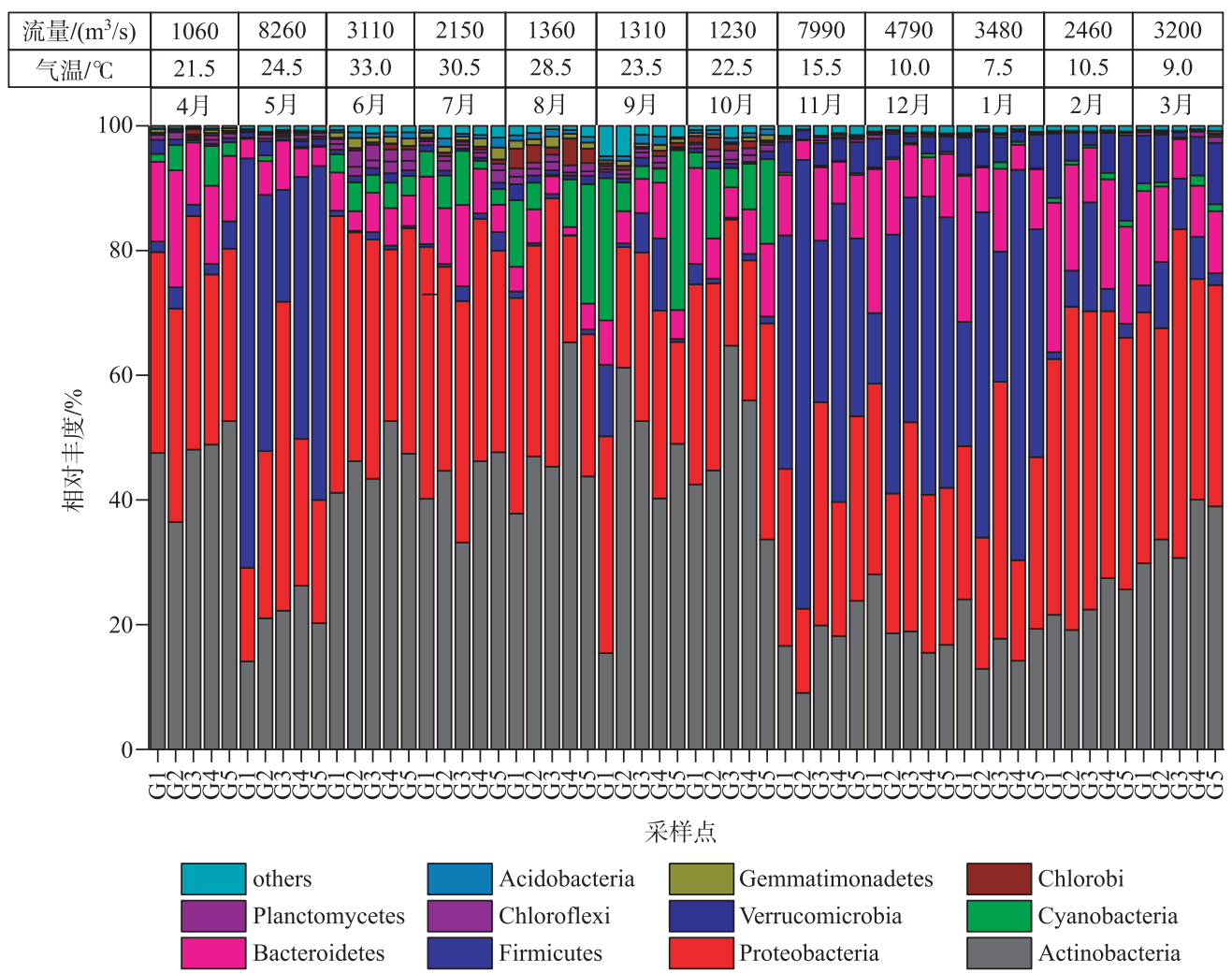

图 4 赣江水体细菌门水平分类

Fig.4 The bacterial phyla during the water of the sample ID in the Ganjiang River

$($ 相关系数 $=0.6249)$; 气温、流量和 DOC 是影响门水平细菌群落结构组成最佳环境因子组合 $($ 相关系数 $=$ $0.5932)$.

通过环境因子对主要门分类种群 (平均丰度大于 $0.50 \%$ ) 的 RDA 分析发现, 第 1 个维度解释了细菌群 落结构组成变异程度的 $60.60 \%$, 第 2 个维度解释了 $7.30 \%$, 两者共解释了 $67.90 \%$. 对细菌群落一环境关系显 著贡献的环境变量是流量 $(P=0.002)$ 、气温 $(P=0.002) 、 \mathrm{Cl}^{-}(P=0.002)$ 和 $\mathrm{EC}(P=0.004) . \mathrm{NH}_{4}^{+}-\mathrm{N}$ 和 DOC 的 影响显著性 $P$ 值大于 0.050 . 所以流量、气温、 $\mathrm{Cl}^{-}$和 $\mathrm{EC}$ 是影响主要门分类细菌的显著环境因子. 除 Firmicutes、Verrucomicrobia、Bacteroidetes 和 Proteobacteria, 其他门与气温呈正相关. Firmicutes 和 Verrucomicrobia 与流量呈正相关. 相对丰度最高的 Actinobacteria 与流量呈负相关, 与气温呈正相关; Proteobacteria 是 唯一与气温和流量都呈负相关的门; Firmicutes 与流量呈明显正相关, Bacteroidetes 与气温呈负相关, 但与流 量的相关性较弱 (图 6).

\section{5 城区对细菌群落结构组成的影响}

SourceTracker 模型计算得到南昌城区对赣江河水细菌群落结构组成的影响范围为 6.33\% 34.67\%. 城 市对细菌群落的影响在月份之间没有显著差异 $(P=0.950)$, 但在采样点之间差异显著 $(P=0.013)$. 南昌城 区对采样点 $\mathrm{G} 3(19.67 \%)$ 的影响显著高于 $\mathrm{G} 2(14.50 \%, P=0.028) 、 \mathrm{G} 4(13.03 \%, P=0.005)$ 和 $\mathrm{G} 5(12.69 \%, P=$ 0.004 ); 对采样点 $\mathrm{G} 2 、 \mathrm{G} 4$ 和 G5 的影响没有显著差异 (图 7a). 模型结果表明南昌城区对赣江南支的细菌群 落影响更明显.

不同采样点 3 种污水指示细菌 Acinetobacter、Arcobacter 和 Mycobacterium 在 G3 采样点的相对丰度最高 $(41.67 \%)$, 其次为 $\mathrm{G} 2(24.09 \%) 、 \mathrm{G} 4(12.38 \%) 、 \mathrm{G} 5(11.64 \%)$ 和 $\mathrm{G} 1(10.21 \%) . \mathrm{G} 3$ 采样点污水细菌数显著高 于 $\mathrm{G1}(P=0.030) 、 \mathrm{G} 4(P=0.024)$ 和 $\mathrm{G} 5(P=0.021)$, 但不显著高于 $\mathrm{G} 2(P=0.320)$ (图 7b). 不同采样点污水 


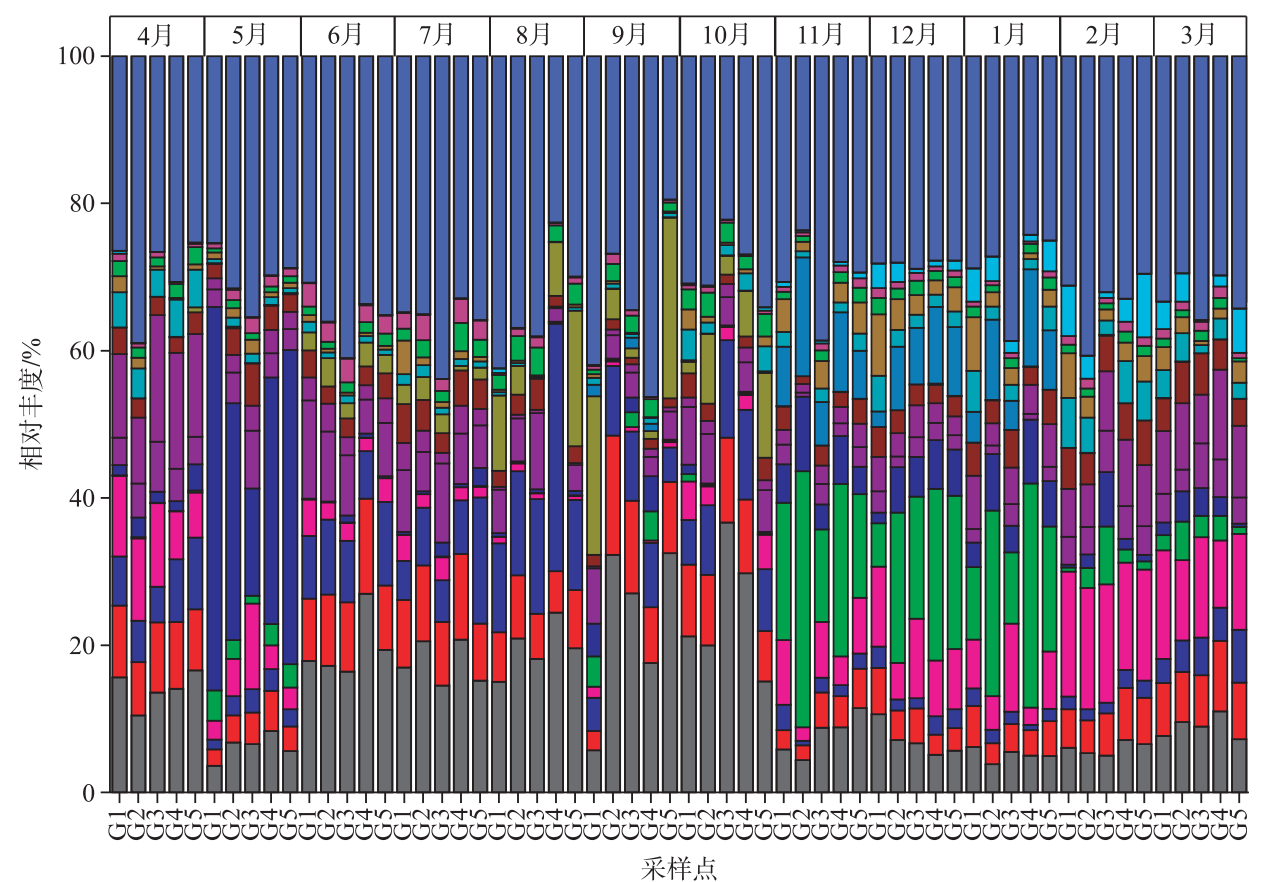

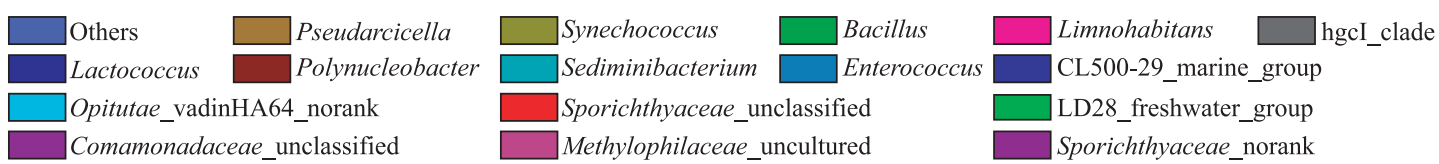

图 5 赣江水体细菌属水平分类 (others 表示平均丰度低于 $1 \%$ 的部分; norank 表示位于分类学数据库 分类学谱系的中间等级没有科学名称; uncultured 表示未培养细菌; unclassified 表示属分类级别分值较低)

Fig.5 The bacterial genera during the water of the sample ID in the Ganjiang River

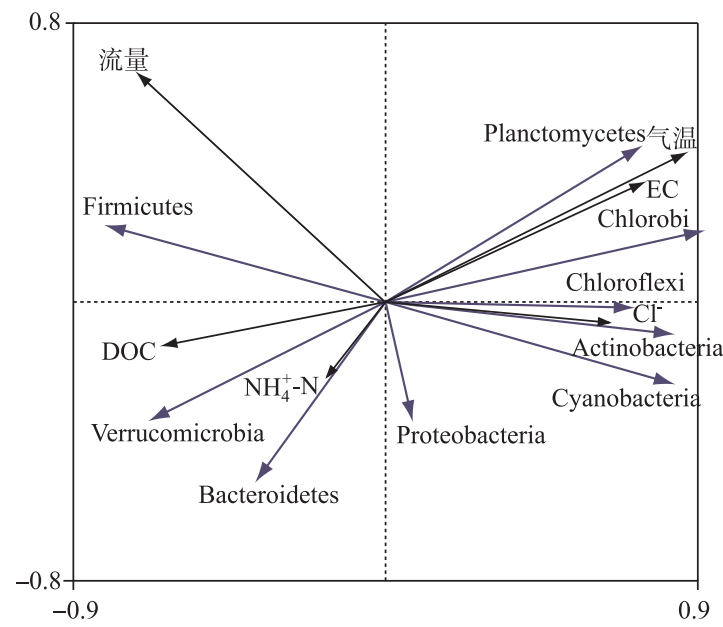

图 6 细菌门分类群落与环境因子的 RDA 分析

Fig.6 RDA biplot of bacterial phyla and environmental factors

细菌序列数差异与 SourceTracker 结果相近, 表明 SourceTracker 模型的计算结果是可靠的. 

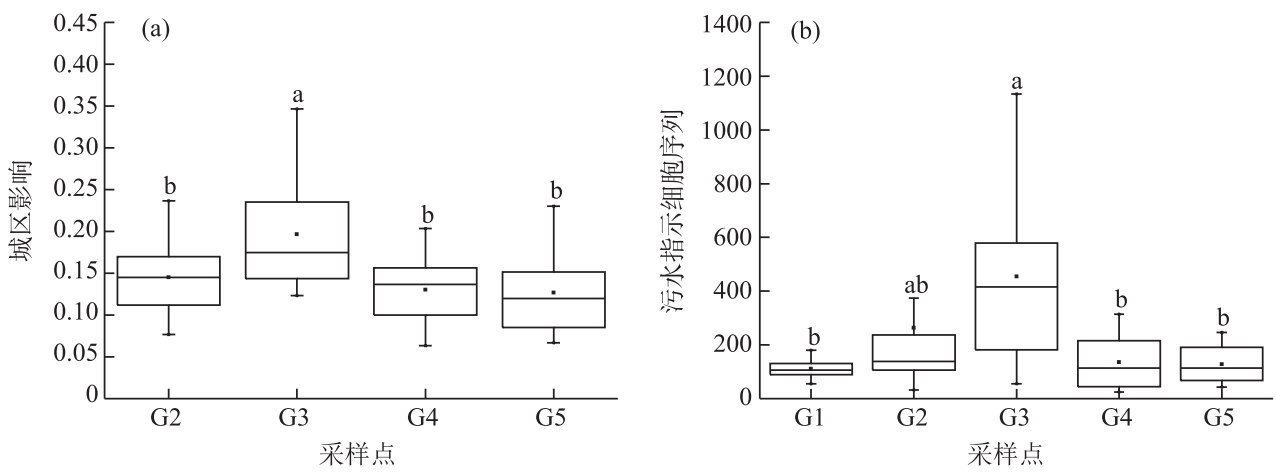

图 7 城区对赣江水体细菌群落结构组成的影响 (a) 及不同采样点 3 种污水指示细菌序列数 (b) 箱线图 ( 图中不同字母表示采样点间显著性 ( $\mathrm{LSD}$ 检验, $P<0.05$ ))

Fig.7 Effects of urban area on bacteria community (a) and sequence number of sewage indicator bacteria in different sample IDs (b) (Different letters indicate significant differences among sample IDs ( LSD test, $P<0.05)$ )

\section{3 讨论}

本次研究中河水中最丰富的门是 Actinobacteria (34.05\%) 和 Proteobacteria (31.59\% ),两者占总基因序列 的比例达到了 $65.64 \%$. 这和以前多数研究结果一致 (表 3$)^{[6,15,35-36]}$. 但与以前研究中 Firmicutes 丰度较 低 ${ }^{[5,12,15]}$ 不同,在本次研究中发现 Firmicutes 在流量较大的月份丰度明显升高, 5 月暴雨后甚至成为河水丰 度最高的门类 $(44.05 \%)$. Lactococcus 在 5 月占 Firmicutes 的 $79.43 \%$, 而 Bacillus 在 $11 、 12$ 和 1 月分别占 $48.89 \%$ 、 48.35\% 和 48.00\%. 因此 Lactococcus 和 Bacillus 的增多是 Firmicutes 比例增大的主要原因. Lactococcus 广泛存在于植物和动物的表层 ${ }^{[37]}, 5$ 月份水热组合好, 动植物生命力强, Firmicutes 比例增大可能是暴雨将 大量动植物表层的 Lactococcus 冲人河中导致的. Bacillus 主要以腐质物为食, 对低温环境具有较强的抵抗 力 $^{[38]}$, 在气温较低的 $11 、 12 、 1$ 月份取代 Lactococcus 成为暴雨洪水中 Firmicutes 的主要组成.

河水细菌群落受多种环境因子的影响, 不同研究中得到结论差别较大 (表 3). 单次采样往往得到水化 学指标是影响河水细菌群落结构组成的主要因素, 如 $\mathrm{Liu}$ 等 ${ }^{[6]}$ 对东江研究发现氮营养盐是影响细菌群落的 主要因素. 唐婧等 ${ }^{[5]}$ 对南明河研究发现细菌群落的主要影响因子是总氮和总磷. 但多次采样往往发现水文 气象因素是细菌群落结构组成的主要影响因素 ${ }^{[13-15]}$. 本次研究重点对比水文气象条件 (气温和流量) 和水化

表 3 国内外河流基于 $16 \mathrm{~S}$ rRNA 方法的细菌群落及影响因子研究结果

Tab.3 Bacteria communities and the influencing factors in domestic and oversea rivers based on 16S rRNA

\begin{tabular}{|c|c|c|c|}
\hline 河流 & 河段/采样点 * 采样次数 & 门分类优势细菌(按丰度由大到小排列) & 主要影响因子 \\
\hline 珠江 $^{[13]}$ & 珠江口/6*2 & Gammaproteobacteria Bacteroidetes 、Alphaproteobacteria & 气温、营养盐 \\
\hline 东江 ${ }^{[6]}$ & 下游/9*1 & Proteobacteria、Actinobacteria、Bacteroidetes & $\mathrm{NH}_{4}^{+}-\mathrm{N} 、 \mathrm{NO}_{3}^{-}-\mathrm{N}$ \\
\hline 黄河 ${ }^{[10]}$ & 中下游 $/ 6 * 1$ & Proteobacteria 、Bacteroidetes 、Acidobacteria & $\mathrm{pH} 、 \mathrm{DOC} 、$ 含沙量 \\
\hline 南明河 ${ }^{[5]}$ & 贵阳城区 $/ 5 * 1$ & Proteobacteria $、$ Planctomycetes 、Bacteroidetes & $\mathrm{TN} 、 \mathrm{TP}$ \\
\hline 朝阳河 ${ }^{[14]}$ & 上海城区 $/ 6 * 5$ & - & 气温、TDS、pH、TP \\
\hline 松花江 ${ }^{[36]}$ & 上游至下游 $/ 5 * 1$ & Proteobacteria 、Actinobacteria、Cyanobacteria & - \\
\hline 多瑙河 ${ }^{[35]}$ & 上游至下游 $/ 75 * 1$ & Actinobacteria 、Proteobacteria、Bacteroidetes & 水文条件 \\
\hline 泰晤士河 $^{[4]}$ & 上游至下游 $/ 23 * 1$ & Actinobacteria 、Bacteroidetes 、Proteobacteria & 河水滞留时间 \\
\hline 西诺斯河 ${ }^{[12]}$ & 上游至下游/ $14 * 2$ & Proteobacteria 、Bacteroidetes、Actinobacteria & 河水补给 \\
\hline 密西西比河 ${ }^{[15]}$ & 上游 $/ 8 * 3$ & Proteobacteria、Actinobacteria、Bacteroidetes & 气温、流量、营养盐 \\
\hline
\end{tabular}

“一”表示文献中没有数据. 
学指标的影响. 研究中尽可能多地检验了水化学指标, 包括营养盐 ( DOC、 $\mathrm{TP}$ 和 $\mathrm{NH}_{4}^{+}-\mathrm{N}$ )、水化学离子 $\left(\mathrm{HCO}_{3}^{-} 、 \mathrm{Cl}^{-} 、 \mathrm{NO}_{3}^{-} 、 \mathrm{SO}_{4}^{2-} 、 \mathrm{Na}^{+} 、 \mathrm{~K}^{+}\right.$和 $\left.\mathrm{Mg}^{2+}\right)$ 和重金属元素 $(\mathrm{Mn} 、 \mathrm{Cd} 、 \mathrm{Cr} 、 \mathrm{~Pb} 、 \mathrm{Cu} 、 \mathrm{As} 、 \mathrm{Ba}$ 和 $\mathrm{Fe})$; 结果显示气温和流 量对细菌群落的影响大于水化学指标. 气温影响细菌的生长速度 ${ }^{[39]}$, 对河流细菌群落有着重要影响; 流量 影响河水补给来源和细菌的运动能力 ${ }^{[4,12]}$, 对某些类型细菌如 Firmicutes 影响明显. Proteobacteria 是唯一与 气温和流量都呈负相关的门, Proteobacteria 是城市污水的指示细菌之一 ${ }^{[18,33]}, 2015-2016$ 年是超强“厄尔尼 诺” 年, 降水异常 ${ }^{[27]}$, 流量较往年偏高. 流量大对城市排放污水的稀释作用强, Proteobacteria 丰度低. Proteobacteria 对气温具有敏感性, 对低温的适应能力强, 相对丰度与气温呈负相关关系 ${ }^{[40-41]}$.

城市废水的排放会导致污水细菌直接进人河流 ${ }^{[33]}$ 或通过河水物理化学参数而影响细菌群落 ${ }^{[20]}$. 本次 研究中, 除 Proteobacteria $(P=0.016)$ 外, 其余门的细菌相对丰度在 5 个采样点之间不存在显著差异, 南昌城 区对赣江细菌群落没有明显改变. SourceTracker 模型结果表明, 南昌城区对 G3 采样点细菌群落的影响最大 $(19.67 \%)$, 其次为 G2 $(14.50 \%) 、 G 4(13.03 \%)$ 和 G5 (12.69\%) 采样点. G3 采样点位于流经老城区和高新技 术开发区的赣江南支, 流经城区长度最长, 受城区影响也最大. 污水指示细菌丰度也表明赣江南支受城区影 响最大.

\section{4 结论}

1) 赣江南昌段的优势菌门为 Actinobacteria (34.05\%) 和 Proteobacteria (31.59\%), 其次为 Firmicutes $(15.49 \%)$ 和 Bacteroidetes $(9.12 \%)$. Firmicutes 在流量较大的月份丰度明显升高, 5 月暴雨后甚至成为河水丰 度最高的门类 $(44.05 \%)$. Lactococcus 和 Bacillus 的增多是 Firmicutes 比例增大的主要原因.

2)气温和流量是河流细菌群落主要影响因子, 其中气温是影响 OTU 丰度的最佳单参数, 流量是影响门 丰度的最佳单参数. 水文气象条件 (气温和流量) 对河流细菌群落的影响大于水化学指标, 包括营养盐 $\left(\mathrm{DOC} 、 \mathrm{TP}\right.$ 和 $\left.\mathrm{NH}_{4}^{+}-\mathrm{N}\right)$ 、水化学离子 $\left(\mathrm{HCO}_{3}^{-} 、 \mathrm{Cl}^{-} 、 \mathrm{NO}_{3}^{-} 、 \mathrm{SO}_{4}^{2-} 、 \mathrm{Na}^{+} 、 \mathrm{~K}^{+}\right.$和 $\left.\mathrm{Mg}^{2+}\right)$ 和重金属元素 $(\mathrm{Mn} 、 \mathrm{Cd} 、 \mathrm{Cr} 、 \mathrm{~Pb} 、$ $\mathrm{Cu} 、 \mathrm{As} 、 \mathrm{Ba}$ 和 $\mathrm{Fe}$ ).

3 ) 南昌城区对细菌群落的影响较小 $(6.33 \% \sim 34.67 \%)$. 除 Proteobacteria $(P=0.016)$ 外, 其余门的细菌相 对丰度在 5 个采样点之间不存在显著差异, 南昌城区对赣江细菌群落没有明显改变. SourceTracker 模型结果 表明南昌城区对赣江南支的细菌群落改变显著高于其他河段, 主要的影响门类为 Proteobacteria.

\section{5 参考文献}

[ 1 ] Findlay S. Stream microbial ecology. Journal of the North American Benthological Society, 2010, 29(1): 170-181.

[ 2 ] Caporaso JG, Lauber CL, Walters WA et al. Global patterns of 16S rRNA diversity at a depth of millions of sequences per sample. Proceedings of the National Academy of Sciences, 2011, 108(1) : 4516-4522.

[ 3 ] Glenn TC. Field guide to next-generation DNA sequencers. Molecular Ecology Resources, 2011, 11(5) : 759-769.

[ 4 ] Read DS, Gweon HS, Bowes MJ et al. Catchment-scale biogeography of riverine bacterioplankton. Isme Journal, 2015,9 (2) : 516-526.

[ 5 ] Tang J, Xu XR, Shang CY et al. Association of bacterial diversity in city area of Nanming river with environmental factors. Acta Microbiologica Sinica, 2015, 55(8): 1050-1059. [唐婧, 徐小蓉, 商传禹等. 南明河城区河段细菌多样性与环 境因子的关系. 微生物学报, 2015, 55(8): 1050-1059.]

[ 6 ] Liu Z, Huang S, Sun G et al. Phylogenetic diversity, composition and distribution of bacterioplankton community in the Dongjiang River, China. FEMS Microbiology Ecology, 2012, 80(1) : 30-44.

[ 7 ] Shen S, Yang CM, Cheng SP. Spatial characteristics analysis by PCR-DGGE for bacterial communities in surface sediments of Tangxi River, Hefei City. Chinese Journal of Applied and Environmental Biology, 2015, 21(1): 80-87. [沈炼, 杨长明, 成水平. PCR-DGGE 分析合肥市塘西河表层沉积物细菌群落结构空间分布特征. 应用与环境生物学报, $2015,21(1): 80-87$.

[ 8 ] Sun HM, Bai JJ, Sun WL et al. Quantitative and qualitative analysis of total bacteria and ammonia-oxidizing bacteria in Buji River in wet Season. Environmental Science, 2012, 33(8): 2691-2700. [孙海美, 白姣姣, 孙卫玲等. 布吉河丰水 期总细菌和氨氧化细菌的定性和定量研究. 环境科学, 2012, 33(8) : 2691-2700.] 
[ 9 ] Fortunato CS, Eiler A, Herfort L et al. Determining indicator taxa across spatial and seasonal gradients in the Columbia River coastal margin. Isme Journal, 2013, 7(10) : 1899-1911.

[10] Xia N, Xia X, Liu T et al. Characteristics of bacterial community in the water and surface sediment of the Yellow River, China, the largest turbid river in the world. Journal of Soils and Sediments, 2014, 14(11) : 1894-1904.

[11] Staley C, Gould TJ, Wang P et al. Bacterial community structure is indicative of chemical inputs in the Upper Mississippi River. Frontiers in Microbiology, 2014, 5(8) : 524.

[12] De Oliveira LF, Margis R. The Source of the river as a nursery for microbial diversity. PLoS One, 2015, 10 (3) : e0120608.

[13] Zhang W, Bougouffa S, Wang Y et al. Toward understanding the dynamics of microbial communities in an Estuarine System. PloS One, 2014, 9(4): e94449.

[14] Zhang M, Yu N, Chen L et al. Structure and seasonal dynamics of bacterial communities in three urban rivers in China. Aquatic Sciences, 2012, 74(1) : 113-120.

[15] Staley C, Gould TJ, Wang P et al. Species sorting and seasonal dynamics primarily shape bacterial communities in the Upper Mississippi River. Science of the Total Environment, 2015, 505: 435-445.

[16] Kolmakova OV, Gladyshev MI, Rozanov AS et al. Spatial biodiversity of bacteria along the largest Arctic river determined by next-generation sequencing. Fems Microbiology Ecology, 2014, 89(2) : 442-450.

[17] Ye L, Zhang T. Bacterial communities in different sections of a municipal wastewater treatment plant revealed by 16S rDNA 454. pyrosequencing. Applied Microbiology and Biotechnology, 2013, 97(6) : 2681-2690.

[18] Shanks OC, Newton RJ, Kelty CA et al. Comparison of the microbial community structures of untreated wastewaters from different geographic locales. Applied and Environmental Microbiology, 2013, 79(9) : 2906-2913.

[19] Lin Y, Li D, Zeng S et al. Changes of microbial composition during wastewater reclamation and distribution systems revealed by high-throughput sequencing analyses. Frontiers of Environmental Science and Engineering, 2016, 10(3): 539-547.

[20] Paul M, Meyer J. Streams in the urban landscape. Urban ecology: An international perspective on the interaction between humans and nature. Springer US, 2008: 207-231.

[21] Ji Y, Zhang J, Huang X et al. Investigation and assessment of heavy metals in surface sediments of Ganjiang River, China. Journal of Environmental Biology, 2014, 35(6) : 1173-1179.

[22] Li X, Zhang L, Yang G et al. Impacts of human activities and climate change on the water environment of Lake Poyang Basin, China. Geoenvironmental Disasters, 2015, 2(1): 22.

[23] Wang P, Chen DD, Chen B. The distribution characters and pollution sources of nitrogen and phosphorus nutrients in Ganjiang River. Journal of Jiangxi Normal University: Natural Science, 2015, 39(4) : 435-440. [王鹏, 陈多多, 陈波. 贑江 水体氮磷营养盐分布特征与污染来源. 江西师范大学学报: 自然科学版, 2015, 39(4) : 435-440.]

[24] Xu LK, Wang QJ, Xiang SL et al. On impact of non-point source pollution in Ganjiang downstream. Journal of East China Jiaotong University, 2012, 29(1):48-53. [徐刘凯, 王全金, 向速林等. 赣江下游地区各类非点源污染源的影响研 究. 华东交通大学学报, 2012, 29(1): 48-53.]

[25] Wang P, Qi SH, Chen B. Influence of land use on river water quality in the Ganjiang basin. Acta Ecologica Sinica, 2015, 35(13) : 4326-4337. [王鹏, 齐述华, 陈波. 赣江流域土地利用方式对河流水质的影响. 生态学报, 2015, 35(13): 4326-4337.

[26] Zhang BJ, Zhu MM, Wang P et al. Spatial and temporal distribution of dissolved cadmium in and water quality assessment of the water body of the Ganjiang River catchment. Journal of Ecology and Rural Environment, 2014, 30(4) : 495-499. [张宝军, 朱蒙曼, 王鹏等. 赣江流域水体中可溶态镉的时空分布特征及水质评价. 生态与农村环境学报, 2014, 30(4) : 495-499.]

[27] Li QQ, Mi QY. Dialogue Zhang Renhe: China Southern heavy rainfall and super El Niño in the first half of 2016. Chinese Science Bulletin, 2016, 61(24) : 2659-2662. [李清泉, 闵庆烨. 对话张人禾: 2016 年上半年中国南方强降水与超强 厄尔尼诺. 科学通报, 2016, 61(24): 2659-2662.]

[28] Bray JR, Curtis JT. An ordination of the upland forest communities of Southern Wisconsin. Ecological Monographs, 1957, $27(4)$ : 326-349.

[29] Oksanen J, Kindt R, Legendre P et al. Vegan: community ecology package: R package version 1.13-1. R Foundation for 
Statistical Computing, Vienna. Http://vegan.r-forge.r-project.org/.

[30] Clarke KR, Ainsworth M. A method of linking multivariate community structure to environmental variables. Marine Ecology Progress, 1993, 92(3) : 205-219.

[31] Knights D, Kuczynski J, Charlson ES et al. Bayesian community-wide culture-independent microbial source tracking. Nature Methods, 2011, 8(9): 761-763.

[32] Sun H, He X, Ye L et al. Diversity, abundance, and possible sources of fecal bacteria in the Yangtze River. Applied Microbiology and Biotechnology, 2017, 101(5) : 2143-2152.

[33] Newton RJ, Bootsma MJ, Morrison HG et al. A microbial signature approach to identify fecal pollution in the waters off an urbanized coast of Lake Michigan. Microbial Ecology,2013, 65(4) : 1011-1023.

[34] Comte J, Berga M, Severin I et al. Contribution of different bacterial dispersal sources to lakes: Population and community effects in different seasons. Environmental Microbiology, 2017, 19(6): 2391-2404.

[35] Savio D, Sinclair L, Ijaz UZ et al. Bacterial diversity along a $2600 \mathrm{~km}$ river continuum. Environmental Microbiology, 2015, 17(12) : 4994-5007.

[36] Ding C, Chang YM, Yang Q et al. Bacterial biodiversity in the river in Northeast China during the freezing seasons: A case in Songhua River. Acta Scientiae Circumstantiae, 2012, 32(6): 1415-1423. [丁珵, 常玉梅, 杨琦等. 我国东北典型河 流冰封期细菌多样性的研究一一松花江为例. 环境科学学报, 2012, 32(6)：1415-1423.]

[37] Kim W ed. The genus Lactococcus. Lactic Acid Bacteria: Biodiversity and Taxonomy, John Wiley and Sons, Ltd, 2014: 429-443.

[38 ] Dolin'Ska M, Berthold A. Characteristics of the temperature growth of the Bacillus cereus isolated from different environments. Medycyna Weterynaryjna, 2008, 64(8): 1016-1018.

[39] Sieburth JM. Seasonal selection of estuarine bacteria by water temperature. Journal of Experimental Marine Biology and Ecology, 1967, 1(1) : 98-121.

[40] Eronenrasimus E, Lyra C, Rintala JM et al. Ice formation and growth shape bacterial community structure in Baltic Sea drift ice. Fems Microbiology Ecology, 2015, 91(2) : 1-13.

[41] Wu J, Xiong J, Hu C et al. Temperature sensitivity of soil bacterial community along contrasting warming gradient. Applied Soil Ecology, 2015, 94: 40-48. 